\title{
Stable transfection and identification of a hair follicle-specific expression vector of IGFBP-5 in goat fetal fibroblasts
}

\author{
X.J. Wang*, H.M. Su*, Y. Liang, Y.F. Wang, X.D. Guo, Z.G. Wang and \\ D.J. Liu
}

Key Laboratory of Mammal Reproductive Biology and Biotechnology of the Ministry of Education, College of Life Sciences, Inner Mongolia University, Hohhot, China

*These authors contributed equally to this study.

Corresponding author: Z.G. Wang

E-mail: 1swzg@imu.edu.cn

Genet. Mol. Res. 13 (1): 1885-1892 (2014)

Received January 17, 2013

Accepted August 15, 2013

Published March 17, 2014

DOI http://dx.doi.org/10.4238/2014.March.17.16

\begin{abstract}
The insulin-like growth factor-binding protein-5 (IGFBP-5) is one of the 6 members of the IGFBP family and is involved in the regulation of cell growth, apoptosis, and other IGF-stimulated signaling pathways. To determine the significance of IGFBP-5 in the Inner Mongolia Cashmere goat (Capra hircus), a hair follicle-specific expression vector of IGFBP-5, pCDsRed2-K-IGFBP5 (6.7 kb), was constructed by cloning IGFBP-5 downstream of the keratin-association protein (KAP)6-1 promoter and inserting this fragment into pCDsRed2, which contains a red fluorescent protein (DsRed) expression unit. Inner Mongolia Cashmere goat fetal fibroblast (GFb) cells were transfected with the expression vector by using Lipofectamine ${ }^{\mathrm{TM}} 2000$. Cell clones that stably expressed red fluorescence were obtained after selection with Geneticin (G418). The transgene in the cell clones was examined by polymerase chain reaction to verify that exogenous DNA (pKAP6-1 and IGFBP-5) had integrated stably into GFb cells. These data suggest
\end{abstract}


that this method can be used for the construction of a hair folliclespecific expression vector for functional genetic analyses and for obtaining stable transfection donor cells for nuclear transfer.

Key words: Inner Mongolia Cashmere goat; IGFBP-5; Hair follicle-specific expression vector; Stable transfection

\section{INTRODUCTION}

Insulin-like growth factor-binding proteins (IGFBPs) constitute a family of secreted proteins that bind insulin-like growth factors I and II (IGF-I and -II). IGFBPs modulate the effects of IGFs on target cells (James et al., 1993). IGFBP-5 is a critical, and the most evolutionarily conserved, member of the IGFBP family (Allander et al., 1994; Beattie et al., 2006), and is involved in many processes, including bone, ovary, mammary gland, and kidney physiology (Kelley et al., 1996). IGFBP-5 primarily mediates cell growth, suppressing or inducing proliferation (Andress and Birnbaum, 1992; Ewton et al., 1998; Meadows et al., 2000; Schneider et al., 2001).

IGFBP-5 is also associated with the development and differentiation of hair; however, the underlying mechanisms have not yet been examined. Hair features are affected by many factors, the two most significant of which being the follicle's capacity and the hair growth cycle. IGF-I signaling is an important mitogenic and morphogenetic regulator in hair follicle biology (Weger and Schlake, 2005). IGFBP-5 regulates the hair shaft structure and follicle identity (Schlake, 2005b), and was identified as the first molecular marker in zigzag hair follicles (Schlake, 2005b). In 2006, Schlake reported Krox-20 as a molecular marker, whose expression in the proximal follicle was restricted to zigzag hair follicles, implicating it as a nodal point of the fibroblast growth factor and IGF signaling pathways, which control IGFBP-5 expression and, therefore, possibly affect the periodicity of the zigzag hair phenotype.

$I G F B P-5$ has been cloned in humans, mice, and rats, but little is known about its function in small ruminants. Specifically, the function of IGFBP-5 in goat cells is currently unknown. In this study, we constructed a hair follicle-specific expression vector of $I G F B P-5$ and stably transfected it into goat fetal fibroblast $(\mathrm{GFb})$ cells. Our data provide a method of constructing a hair follicle-specific expression vector for functional genes and for obtaining stable transfection donor cells for nuclear transfer. Furthermore, results of this study will facilitate further research of the function of IGFBP-5 in hair follicle development and hair features.

\section{MATERIAL AND METHODS}

\section{Cell culture conditions}

Inner Mongolia Cashmere GFb cells were maintained as monolayer cultures in Dulbecco's modified Eagle's medium/Ham's F12 (DMEM/F12; Gibco, Paisley, UK), supplemented with 10\% fetal bovine serum (FBS; Hyclone Laboratories Inc., Logan, UT, USA), 100 $\mathrm{U} / \mathrm{mL}$ penicillin $\mathrm{G}$, and $100 \mathrm{mg} / \mathrm{mL}$ streptomycin (Sigma-Aldrich, Inc., St. Louis, MO, USA). Cell cultures were maintained and incubated at $37^{\circ} \mathrm{C}$ in humidified air with $5 \% \mathrm{CO}_{2}$. 


\section{Construction of pCDsRed2-IGFBP5}

The pDsRed2-1 vector, containing a red fluorescent protein (DsRed), was used to generate pCDsRed2, in which the cytomegalovirus (CMV) promoter was placed upstream of the DsRed2 gene (Guo et al., 2009). pMD19T-IGFBP5 was digested with SalI and KpnI, and an IGFBP-5 fragment was cloned into pCDsRed2 to generate pCDsRed2-IGFBP5. Recombinant plasmids were verified by restriction analysis on a UV transilluminator (UVItec, London, UK) after electrophoresis.

\section{Construction of the skin-specific expression vector, pCDsRed2-K-IGFBP5}

pMD19TK was digested with EcoRI and SalI (TaKaRa, Dalian, China) to yield the keratin-associated protein (KAP)6-1 fragment, which was cloned into pCDsRed2-IGFBP5 to generate pCDsRed2-K-IGFBP5. The recombinant plasmid was verified by restriction analysis on a UV transilluminator (UVItec) after electrophoresis. The map of pCDsRed-K-IGFBP5 is shown in Figure 1.
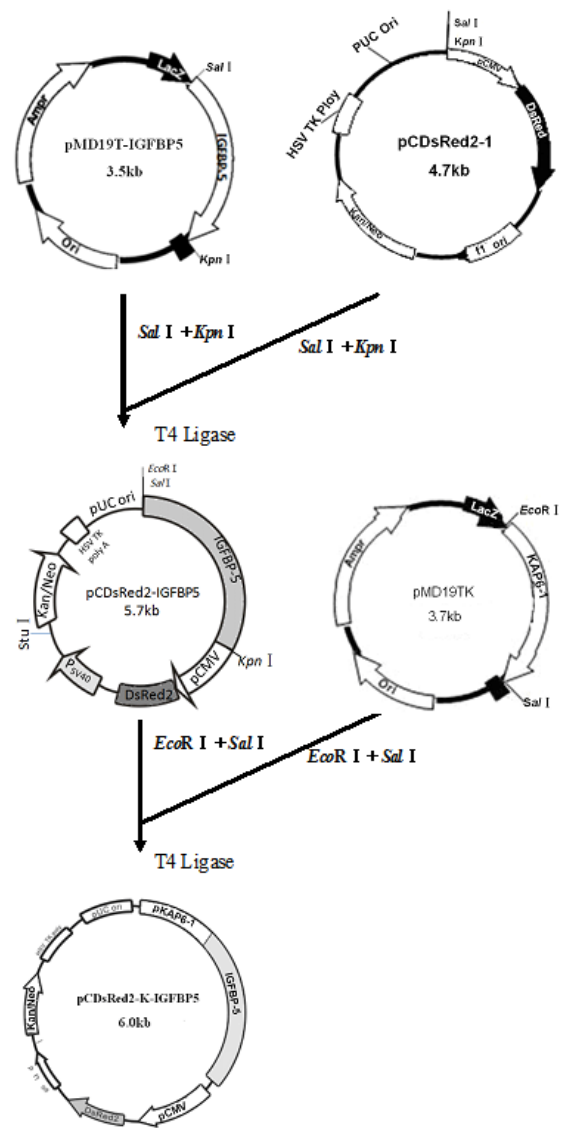

Figure 1. Diagram of hair follicle-specific expression vector pCDsRed-K-IGFBP5. 


\section{Transfection in vitro}

Four micrograms pCDsRed-K-IGFBP5 was added to $8 \mu$ Lipofectamine $^{\mathrm{TM}} 2000$ (Invitrogen, Carlsbad, CA, USA) and mixed with $5 \mathrm{~mL}$ serum-free media. GFb cells were grown from 60 to $70 \%$ confluence on 6 -well plates, and then incubated with this media for $6 \mathrm{~h}$ at $37^{\circ} \mathrm{C}$ and $5 \%$ $\mathrm{CO}_{2}$; empty vector and untransfected cells were used as controls. The medium containing Lipofectamine $^{\mathrm{TM}} 2000$ was removed, and the cells were incubated in DMEM/F12 medium with $10 \%$ FBS. The cells were selected with $800 \mu \mathrm{g} / \mathrm{mL}$ Geneticin (G418; Hyclone Laboratories) $48 \mathrm{~h}$ after transfection, and the medium was replaced on alternate days until cells fluoresced red and green.

\section{Verification of the stably transfected vector in GFbs}

Genomic DNA from stably expressing GFb cells, empty vector-transfected cells, and untransfected cells were examined by polymerase chain reaction (PCR). Inner Mongolia Cashmere goat genomic DNA fragments were amplified using a pair of specific primers based on goat pCDsRed2-K-IGFBP5-forward primer: 5'-CACACCCACACTGAGAGC-3'; reverse primer: 5'-CGATCTCGAACTCGTGGC-3'. The start and end positions are shown in Figure 2.

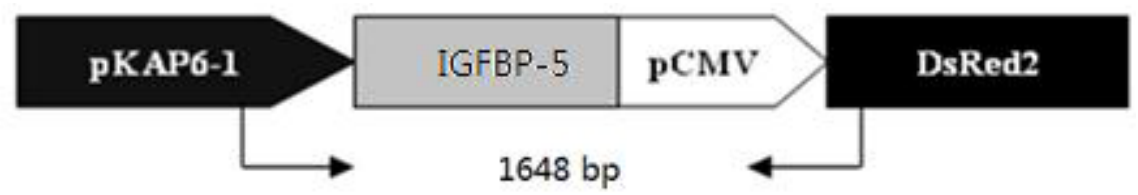

Figure 2. Schematic of PCR.

The PCR was run at $94^{\circ} \mathrm{C}$ for $5 \mathrm{~min}$; followed by 35 cycles of $94^{\circ} \mathrm{C}$ for $1 \mathrm{~min}, 50^{\circ} \mathrm{C}$ for $2.5 \mathrm{~min}$, and $72^{\circ} \mathrm{C}$ for $2.5 \mathrm{~min}$; and $72^{\circ} \mathrm{C}$ for $10 \mathrm{~min}$. PCR mixtures $(25 \mu \mathrm{L})$ contained $0.25 \mu \mathrm{L}$ TaKaRa LA Taq (TaKaRa), $2.5 \mu \mathrm{L}$ 10X LA buffer (TaKaRa), $4 \mu \mathrm{L} 2.5 \mathrm{mM}$ of each dNTP, $0.5 \mu \mathrm{L}$ template DNA, $1 \mu \mathrm{L} 10 \mu \mathrm{M}$ of each primer mixture, and $16.75 \mu \mathrm{L} \mathrm{d}_{3} \mathrm{H}_{2} \mathrm{O}$. PCR products were electrophoresed, and photographs were taken on a UV transilluminator (UVItec). The predicted product length was $1648 \mathrm{bp}$.

\section{RESULTS}

\section{Construction and identification of expression vectors}

To express IGFBP-5, the recombinant plasmid pCDsRed-K-IGFBP5 was constructed, based on the pCDsRed2 backbone. The IGFBP-5 fragment was released from SalI- and KpnI-digested pMD19T-IGFBP5. Then, the IGFBP-5 expression fragment was cloned into pCDsRed2-1 to generate pCDsRed2-IGFBP5. pMD19TK and pCDsRed2-IGFBP5 were digested with EcoRI and SalI, and the KAP6-1 fragment was cloned into pCDsRed2-IGFBP5. The recombinant plasmids were transformed into Escherichia coli. pCDsRed-K-IGFBP5 was identified by restriction analysis (Figure 3). The restriction analysis of pCDsRed2-IGFBP5 is shown in Figure 3A; the IGFBP5 fragment was $816 \mathrm{bp}$. The restriction analysis of pCDsRedK-IGFBP5 is shown in Figure 3B; the KAP6-1 fragment was 1052 bp long. Finally, the plasmids were sequenced, and the correct clones were selected. 


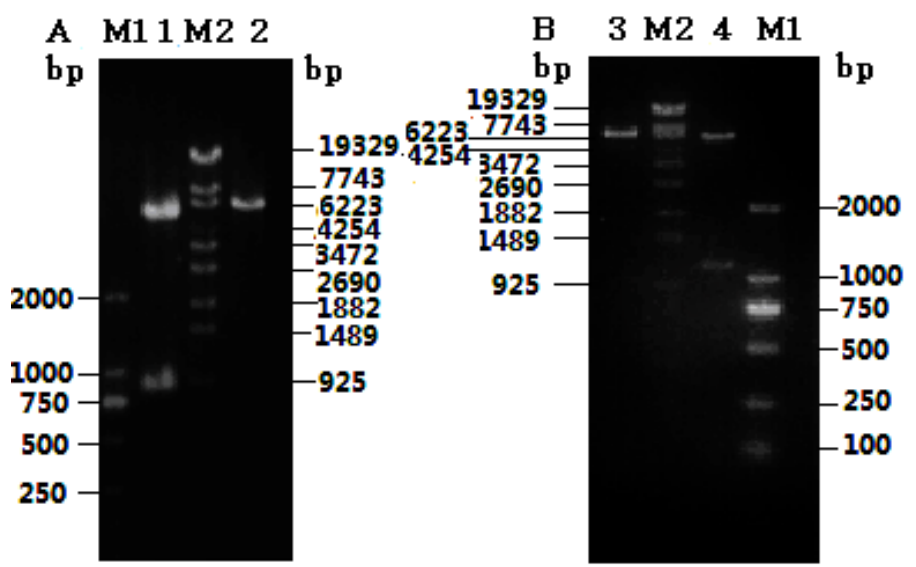

Figure 3. Restriction analysis of pCDsRed2-IGFBP5 (A) and pCDsRed2-K-IGFBP5 (B). A: lane M1 = DL2000 marker; lane $1=$ pCDsRed2-IGFBP5 digested by SalI + KpnI; lane M2 $=\lambda$-EcoT14 I-digested DNA marker; lane 2 $=$ pCDsRed2-IGFBP5 digested by SalI; B: lane $3=$ pCDsRed2-K-IGFBP5 digested by SalI; lane M2 = $\lambda$-EcoT14 I digest DNA marker; lane 4 = pCDsRed2-K-IGFBP5 digested by EcoRI+ SalI; lane M1 = DL2000 marker.

\section{Evaluation of stability for GFbs}

Lipofectamine ${ }^{\mathrm{TM}} 2000$ was used to transfect pCDsRed-K-IGFBP5. An empty vector and untransfected cells were used as controls. The expression of DsRed was visualized under a fluorescence microscope (Olympus IX71, Japan), and photographs were taken using a digital camera. Red fluorescence of the transfected cells was observed $48 \mathrm{~h}$ after transfection. The transfection rate was $9 \%$ (Figure $4 \mathrm{~A}$ and $\mathrm{B}$ ). There were dense areas of fluorescence after selection with G418 for 2 weeks (Figure 4C and D).
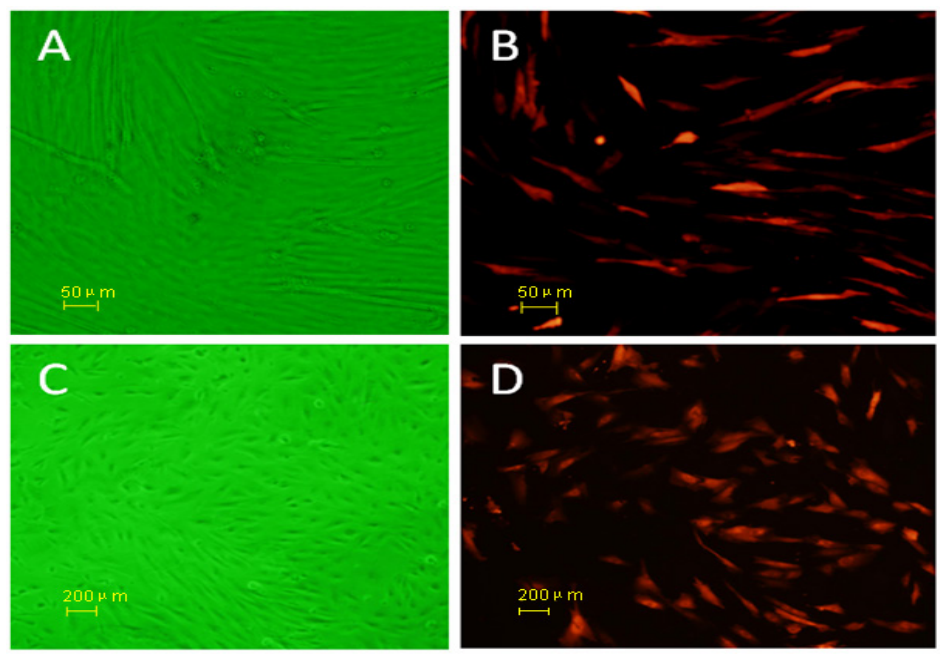

Figure 4. Cells $48 \mathrm{~h}$ and 15 days after transfection. A. Bright-field images of cells (after $48 \mathrm{~h}$ ). B. Red fluorescence of transfected cells (after 48 h). C. Bright-field images of cells (after 15 days). D. Red fluorescence of transfected cells (after 15 days). 


\section{PCR identification of the stably transfected vector in GFbs}

Using primers that spanned KAP6-1 to DsRed2 and genomic DNA from GFb cells as a template, a 1648-bp fragment was amplified; no such fragment was obtained in the control groups (Figure 5). PCR of the target segment in GFb cells demonstrated that goat IGFBP-5 had been transfected into GFb cells and that the transfectants could be used as nuclear donors of transgenic somatic cells.

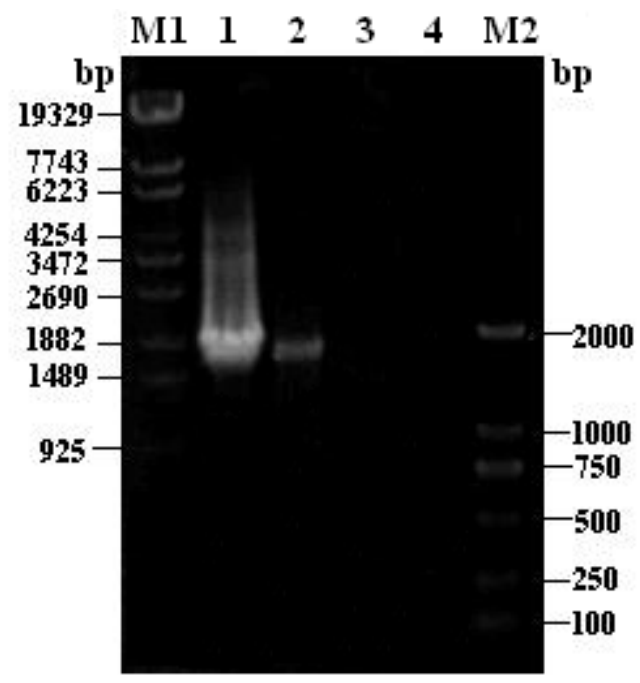

Figure 5. Identification of transgenic cell clones by PCR. Lane $M 1=\lambda$-Ecot14 I-digested DNA marker; lane $1=$ pCDsRed2-K-IGFBP5 plasmid control; lane 2 = pCDsRed2-K-IGFBP5-transfected cells; lane 3 = pCDsRed2transfected cells; lane 4 = untransfected cell control; lane M2 = DL2000 marker.

\section{DISCUSSION}

IGFBP-5 is $17 \mathrm{~kb}$ in length and is located on chromosome 1 in mice (Kou et al., 1994). In humans, it is $33 \mathrm{~kb}$ in length, and lies on chromosome 2 (Allander et al., 1994). IGFBP-5 has a cysteine-rich $N$-terminal domain (12 cysteines) and a cysteine-rich $C$-terminal domain (6 cysteines) (Duan, 2002). The effect of IGFBP-5 on cell survival appears to be based on interactions with specific soluble or cell-associated ligands (Schneider et al., 2002; Beattie et al., 2006; Hung et al., 2008). The $N$ - and $C$-terminal domains are highly conserved among members of the IGFBP family across species (Duan, 2002). The $N$-terminal domain of IGFBP-5 contains the IGF-1-binding region and caveolin-binding sites (Ravid et al., 2008). The $C$ terminal domain cannot bind IGF-1 but can affect the affinity to IGF-1 (Shand et al., 2003). A highly basic domain in the $C$-terminal end of IGFBP-5 (AA220-237) contains a functional nuclear localization sequence (Schedlich et al., 1998).

The hair follicle is primarily an ectodermal derivative with a complex epithelial structure, and it is generated by common progenitor cells. The dermal papilla, which is of mesenchymal origin, can control morphogenesis, hair shaft formation, and hair growth cycles of the 
mature follicle. Several IGF-binding proteins are expressed in the hair follicle, implicating them in hair follicle biology. However, the function of IGF-binding proteins in the hair follicle and skin has not been investigated extensively. IGFBP-3 controls the onset of the regression phase of the hair cycle but is expressed weakly in dermal papilla cells of anagen follicles, and its activity increases dramatically at the end of the growth phase (Schlake et al., 2004). Schlake (2005b) focused on IGFBP-5, which is also expressed in the hair follicle.

During embryogenesis and early postnatal development, 4 hair types are present: guard, awl, zigzag, and auchene (Dry, 1926). IGFBP-5-mediated fibroblast growth factor receptor-3b (FGFR2-IIIb) signals regulate the genetic program that controls the structure of the hair shaft medulla (Schlake, 2005a). Segmental IGFBP-5 expression is specifically associated with the bent structure of zigzag hair and is a central regulator of hair shaft differentiation and hair type determination (Schlake, 2005b). IGFBP-5 mediates the formation of the bent hair structure of zigzag hair. Sriwiriyanont et al. (2011) reported that overexpression of IGFBP-5 in human hair xenografts resulted in twisted hair shafts and unusual deposition of hair cuticles as a consequence of impairments in normal proliferation and differentiation. IGFBP-5 affects human hair shape, and lentiviral transduction can be used to analyze the function of genes in human hair morphogenesis (Sriwiriyanont et al., 2011).

Keratins and KAPs constitute a large, heterogeneous group of proteins that make up approximately $90 \%$ of wool fiber. KAP6-1 is specifically expressed in hair follicles in sheep (McLaren et al., 1997). KAP6 expression begins relatively late in hair follicle differentiation, and the proportion of hair cortical cells that express it varies between follicles (Fratini et al., 1993). Based on the specificity of KAP6-1, the KAP6-1 promoter can be used to affect hair follicle-specific expression of other genes (Guo et al., 2009; Wang et al., 2010); it has been shown to drive downstream gene expression in hair follicles (Wang et al., 2008).

In this study, we demonstrated that our plasmid, in which a neomycin-resistance cassette and a red fluorescent protein are driven by a CMV promoter, is expressed specifically in hair follicles, thereby enhancing the efficiency of screening.

\section{CONCLUSIONS}

Goat IGFBP-5 expression plasmids were constructed and stably transfected into Cashmere goat fetal fibroblasts. DsRed was efficiently expressed in the cells. These data provide a method of constructing a hair follicle-specific expression vector for functional genes, and for obtaining stable transfection donor cells for nuclear transfer.

\section{ACKNOWLEDGMENTS}

Research supported by a grant from the Natural Sciences Foundation of China (\#31160469), the Natural Sciences Foundation of Inner Mongolia, China (\#2011MS0521), and a graduate student research project of the Inner Mongolia University, Major Projects for New Varieties of Genetically Modified Organisms (\#2011ZX08008-002).

\section{REFERENCES}

Allander SV, Larsson C, Ehrenborg E, Suwanichkul A, et al. (1994). Characterization of the chromosomal gene and promoter for human insulin-like growth factor binding protein-5. J. Biol. Chem. 269: 10891-10898. 
Andress DL and Birnbaum RS (1992). Human osteoblast-derived insulin-like growth factor (IGF) binding protein-5 stimulates osteoblast mitogenesis and potentiates IGF action. J. Biol. Chem. 267: 22467-22472.

Beattie J, Allan GJ, Lochrie JD and Flint DJ (2006). Insulin-like growth factor-binding protein-5 (IGFBP-5): a critical member of the IGF axis. Biochem. J. 395: 1-19.

Dry FW (1926). The coat of the mouse (Mus musculus). J. Genet. 16: 287-340.

Duan C (2002). Specifying the cellular responses to IGF signals: roles of IGF-binding proteins. J. Endocrinol. 175: 41-54.

Ewton DZ, Coolican SA, Mohan S, Chernausek SD, et al. (1998). Modulation of insulin-like growth factor actions in L6A1 myoblasts by insulin-like growth factor binding protein (IGFBP)-4 and IGFBP-5: a dual role for IGFBP-5. $J$. Cell. Physiol. 177: 47-57.

Fratini A, Powell BC and Rogers GE (1993). Sequence, expression, and evolutionary conservation of a gene encoding a glycine/tyrosine-rich keratin-associated protein of hair. J. Biol. Chem. 268: 4511-4518.

Guo X, Yin J, Yang D, Mao S, et al. (2009). Construction of a hair-follicle-cell-specific expression vector of IGF-1 and its transfection into caprine fetal fibroblasts cells. Acta Vet. Zootech. Sin. 40: 1460-1467.

Hung PS, Kao SY, Shih YH, Chiou SH, et al. (2008). Insulin-like growth factor binding protein-5 (IGFBP-5) suppresses the tumourigenesis of head and neck squamous cell carcinoma. J. Pathol. 214: 368-376.

James PL, Jones SB, Busby WH Jr, Clemmons DR, et al. (1993). A highly conserved insulin-like growth factor-binding protein (IGFBP-5) is expressed during myoblast differentiation. J. Biol. Chem. 268: 22305-22312.

Kelley KM, Oh Y, Gargosky SE, Gucev Z, et al. (1996). Insulin-like growth factor-binding proteins (IGFBPs) and their regulatory dynamics. Int. J. Biochem. Cell Biol. 28: 619-637.

Kou K, James PL, Clemmons DR, Copeland NG, et al. (1994). Identification of two clusters of mouse insulin-like growth factor binding protein genes on chromosomes 1 and 11. Genomics 21: 653-655.

McLaren RJ, Rogers GR, Davies KP, Maddox JF, et al. (1997). Linkage mapping of wool keratin and keratin-associated protein genes in sheep. Mamm. Genome 8: 938-940.

Meadows KA, Holly JM and Stewart CE (2000). Tumor necrosis factor-alpha-induced apoptosis is associated with suppression of insulin-like growth factor binding protein-5 secretion in differentiating murine skeletal myoblasts. $J$. Cell. Physiol. 183: 330-337.

Ravid D, Chuderland D, Landsman L, Lavie Y, et al. (2008). Filamin A is a novel caveolin-1-dependent target in IGF-Istimulated cancer cell migration. Exp. Cell Res. 314: 2762-2773.

Schedlich LJ, Young TF, Firth SM and Baxter RC (1998). Insulin-like growth factor-binding protein (IGFBP)-3 and IGFBP-5 share a common nuclear transport pathway in T47D human breast carcinoma cells. J. Biol. Chem. 273: 18347-18352.

Schlake T, Beibel M, Weger N and Boehm T (2004). Major shifts in genomic activity accompany progression through different stages of the hair cycle. Gene Expr. Patterns 4: 141-152.

Schlake T (2005a). FGF signals specifically regulate the structure of hair shaft medulla via IGF-binding protein 5 . Development 132: 2981-2990.

Schlake T (2005b). Segmental Igfbp5 expression is specifically associated with the bent structure of zigzag hairs. Mech. Dev. 122: 988-997.

Schlake T (2006). Krox20, a novel candidate for the regulatory hierarchy that controls hair shaft bending. Mech. Dev. 123: 641-648.

Schneider MR, Zhou R, Hoeflich A, Krebs O, et al. (2001). Insulin-like growth factor-binding protein-5 inhibits growth and induces differentiation of mouse osteosarcoma cells. Biochem. Biophys. Res. Commun. 288: 435-442.

Schneider MR, Wolf E, Hoeflich A and Lahm H (2002). IGF-binding protein-5: flexible player in the IGF system and effector on its own. J. Endocrinol. 172: 423-440.

Shand JH, Beattie J, Song H, Phillips K, et al. (2003). Specific amino acid substitutions determine the differential contribution of the $\mathrm{N}$ - and $\mathrm{C}$-terminal domains of insulin-like growth factor (IGF)-binding protein-5 in binding IGF-I. J. Biol. Chem. 278: 17859-17866.

Sriwiriyanont P, Hachiya A, Pickens WL, Moriwaki S, et al. (2011). Effects of IGF-binding protein 5 in dysregulating the shape of human hair. J. Invest. Dermatol. 131: 320-328.

Wang C, An T, Bai X and Ren H (2008). Molecular cloning and activity analysis in sheep fibroblast of the keratin associated protein promoter of the sheep. Chin. J. Vet. Sci. 28: 137-145.

Wang Y, Liang Y, Jin Y and Wang X (2010). Cloning of thymosin $\beta 4$ gene from Inner Mongolia Cashmere goat and its stable transfection into caprine fetal fibroblasts cells. Sci. Agric. Sin. 43: 4497-4504.

Weger N and Schlake T (2005). Igf-I signalling controls the hair growth cycle and the differentiation of hair shafts. $J$. Invest. Dermatol. 125: 873-882. 